\title{
The Value of Paratracheal Lymphadenectomy in Esophagectomy for Adenocarcinoma of the Esophagus or Gastroesophageal Junction: A Systematic Review of the Literature
}

\author{
Amaia Gantxegi, $\mathrm{MD}^{1}$, B. Feike Kingma, $\mathrm{MD}, \mathrm{PhD}^{2}$, Jelle P. Ruurda, Prof. ${ }^{2}$, Grard A. P. Nieuwenhuijzen, MD, \\ $\mathrm{PhD}^{3}$, Misha D. P. Luyer, MD, $\mathrm{PhD}^{3}$, and Richard van Hillegersberg, Prof. Dr. ${ }^{2}$ \\ ${ }^{1}$ Department of Surgery, Vall d'Hebron Hospital Universitari, Barcelona, Spain; ${ }^{2}$ Department of Surgery, University \\ Medical Center Utrecht, Utrecht, The Netherlands; ${ }^{3}$ Department of Surgery, Catharina Hospital Eindhoven, Eindhoven, \\ The Netherlands
}

\begin{abstract}
Background. The role of upper mediastinal lymphadenectomy for distal esophageal or gastroesophageal junction (GEJ) adenocarcinomas remains a matter of debate. This systematic review aims to provide a comprehensive overview of evidence on the incidence of nodal metastases in the upper mediastinum following transthoracic esophagectomy for distal esophageal or GEJ adenocarcinoma.

Methods. A literature search was performed using Medline, Embase and Cochrane databases up to November 2020 to include studies on patients who underwent transthoracic esophagectomy with upper mediastinal lymphadenectomy for distal esophageal and/or GEJ adenocarcinoma. The primary endpoint was the incidence of metastatic nodes in the upper mediastinum based on pathological examination. Secondary endpoints were the definition of upper mediastinal lymphadenectomy, recurrent laryngeal nerve (RLN) palsy rate and survival.

Results. A total of 17 studies were included and the sample sizes ranged from 10-634 patients. Overall, the median incidence of upper mediastinal lymph node metastases was $10.0 \%$ (IQR 4.7-16.7). The incidences of upper mediastinal lymph node metastases were $8.3 \%$ in the 7 studies that included patients undergoing primary
\end{abstract}

(c) The Author(s) 2021

First Received: 21 May 2021

Accepted: 31 August 2021;

Published Online: 29 November 2021

R. van Hillegersberg, Prof. Dr.

e-mail: R.vanHillegersberg@umcutrecht.nl resection (IQR 2.0-16.6), 4,4\% in the 1 study that provided neoadjuvant therapy to the full cohort, and $10.6 \%$ in the 9 studies that included patients undergoing esophagectomy either with or without neoadjuvant therapy (IQR 8.9$15.8 \%$ ). Data on survival and RLN palsy rates were scarce and inconclusive.

Conclusions. The incidence of upper mediastinal lymph node metastases in distal esophageal adenocarcinoma is up to $10 \%$. Morbidity should be weighed against potential impact on survival.

Keywords Esophageal adenocarcinoma .

Upper mediastinal lymphadenectomy · Nodal metastases

Esophagectomy in the context of bi- or trimodality treatment achieves a 5-year survival rate of $40-50 \%$ in patients with locally advanced esophageal cancer. ${ }^{1,2}$ An adequate lymphadenectomy is an essential part of esophagectomy and most surgeons routinely remove at least the abdominal and mediastinal lymph node stations (i.e. two-field lymphadenectomy). ${ }^{3}$ Recent studies emphasized the need for a proper lymph node dissection in esophagectomy, as the lymph node yield is directly related to overall survival. ${ }^{4,5}$ Nonetheless, there is an ongoing debate regarding the mediastinal lymph node stations that should be dissected routinely. Particular disagreement exists on the role of an upper mediastinal lymphadenectomy involving the paratracheal lymph nodes (stations 2 and 4 or 105 and 106 according to the American and Japanese classification systems, respectively). ${ }^{6,7}$ While removal of these stations might improve locoregional control of disease, the paratracheal lymph nodes are located in a complex anatomical area containing the recurrent 
laryngeal nerves and several major vascular structures. ${ }^{8-10}$ A paratracheal lymph node dissection, particularly on the left side, is surgically challenging, especially in the open approach. Hence, the potential oncological merits of paratracheal lymphadenectomy need to be weighed against its possible risks in terms of surgical morbidity.

While upper mediastinal lymph node metastases most often occur with squamous cell carcinoma, several studies have shown that paratracheal lymph node metastases are also found in patients with distal adenocarcinoma, even after neoadjuvant therapy. ${ }^{11-13}$ In this perspective, the entire mediastinal peri-esophageal lymph node network should theoretically be removed to optimize the chances of curation and survival following esophagectomy for both adeno- and squamous cell carcinoma. However, available evidence on this topic is conflicting and there is substantial variation regarding the definition of an upper mediastinal lymphadenectomy. ${ }^{14}$ Moreover, there is controversy regarding the survival benefit of extensive mediastinal lymphadenectomy in patients who received neoadjuvant chemoradiation (nCRT).

To provide an objective overview of current evidence on the clinical value of paratracheal lymphadenectomy for adenocarcinoma of the distal esophagus or gastroesophageal junction (GEJ), a systematic review of the literature was performed.

\section{METHODS}

\section{Search Strategy}

A systematic electronic literature search was performed using MEDLINE (via PubMed), EMBASE and the Cochrane Library. The search terms 'resection', 'esophagectomy', 'esophageal resection', 'oesophagectomy', 'oesophageal resection', 'mediastinal lymph*', 'mediastinal node*', 'paratracheal', 'upper mediastin*', 'high mediastin*', 'upper chest', 'higher chest', 'station 2', 'station 4', '2L', '2R', '4R', '4L', 'station 105', '106recR', '106recL', 'adenocarcinoma', 'distal esophageal tumor*', 'distal esophageal carcinoma', 'esophagogastric junction', 'esophago-gastric junction', 'gastroesophageal junction' and 'gastro-esophageal junction' were used in combination with the Boolean operators 'AND' or 'OR'. A full description of the search strategy is presented in Table 1. Two independent researchers (AG and FK) independently performed the electronic search in December 2020.

\section{Study Selection, Eligibility Criteria}

Titles and abstracts were scrutinized by the same two independent researchers ( $\mathrm{AG}$ and FK) to determine their suitability for inclusion. The full text of potentially relevant

TABLE 1 Search strategy

Search terms

MEDLINE/Pubmed

1. ('resection' OR 'esophagectomy' OR 'esophageal resection' OR 'oesophagectomy' OR 'oesophageal resection')

2. ('mediastinal lymph*' OR 'mediastinal node*' OR 'paratracheal' OR 'upper mediastin*' OR 'high mediastin*' OR 'upper chest' OR 'higher chest' OR 'station 2' OR 'station 4' OR '2L' OR '2R' OR '4R' OR '4L' OR 'station 105' OR '106recR' OR '106recL')

3. ('adenocarcinoma' OR ‘distal esophageal tumor*' OR ‘distal esophageal carcinoma' OR 'esophagogastric junction' OR 'esophago-gastric junction' OR 'gastroesophageal junction' OR 'gastro-esophageal junction')

4. ('lung'[title] OR 'lung cancer' [tiab])

5. \#1 AND \#2 AND \#3 NOT \#4

\section{EMBASE}

('resection':ti,ab,kw OR 'esophagectomy':ti,ab,kw OR 'esophageal resection':ti,ab,kw OR 'oesophagectomy':ti,ab,kw OR 'oesophageal resection':ti,ab,kw) AND ('mediastinal lymph*':ti,ab,kw OR 'mediastinal node*':ti,ab,kw OR 'paratracheal':ti,ab,kw OR 'upper mediastin*':ti,ab,kw OR 'high mediastin*':ti,ab,kw OR 'upper chest':ti,ab,kw OR 'higher chest':ti,ab,kw OR 'station 2':ti,ab,kw OR 'station 4':ti,ab,kw OR '2l':ti,ab,kw OR '2r':ti,ab,kw OR ‘4r':ti,ab,kw OR ‘4l':ti,ab,kw OR 'station 105':ti,ab,kw OR '106recr':ti,ab,kw OR '106recl':ti,ab,kw) AND ('adenocarcinoma':ti,ab,kw OR 'distal esophageal tumor*':ti,ab,kw OR 'distal esophageal carcinoma':ti,ab,kw OR 'esophagogastric junction':ti,ab,kw OR 'esophago-gastric junction':ti,ab,kw OR 'gastroesophageal junction':ti,ab,kw OR 'gastro-esophageal junction':ti,ab,kw) NOT ('lung':ab,ti OR 'lung cancer':ab,ti)

Cochrane Library

'resection' OR ‘esophagectomy' OR 'esophageal resection' OR 'oesophagectomy' OR 'oesophageal resection' in Title Abstract Keyword AND 'mediastinal lymph*' OR 'mediastinal node*' OR 'paratracheal' OR 'upper mediastin*' OR 'high mediastin*' OR 'upper chest' OR 'higher chest' OR 'station 2' OR 'station 4' OR '2L' OR '2R' OR ‘4R' OR ‘4L' OR 'station 105' OR '106recR' OR '106recL' in Title Abstract Keyword AND 'adenocarcinoma' OR 'distal esophageal tumor*' OR 'distal esophageal carcinoma' OR 'esophagogastric junction' OR 'esophago-gastric junction' OR 'gastroesophageal junction' OR 'gastro-esophageal junction' in Title Abstract Keyword NOT 'lung' OR 'lung cancer' in Title Abstract Keyword (word variations have been searched) 
articles was retrieved and assessed for inclusion by the same two authors. All studies reporting on the primary endpoint, i.e. the incidence of pathologically confirmed upper mediastinal lymph node metastases in patients undergoing transthoracic esophagectomy for distal esophageal or GEJ adenocarcinoma, were included. Secondary endpoints included the exact definition of performed upper mediastinal lymphadenectomy, recurrent laryngeal nerve injury rate, and survival. Upper mediastinal lymphadenectomy was defined as part of a total mediastinal lymphadenectomy. ${ }^{13}$ Case reports, studies with fewer than 10 patients, reviews, poster abstracts, animal studies, and non-English-language articles were excluded. If authors from the same institution had published a primary paper and then an updated analysis with a larger patient cohort, the most recent publication was included. The reference list of articles obtained was searched to identify additional articles. Any discordances between the two authors regarding study inclusion were resolved between all coauthors. The quality of all selected articles was scored according to the Centre for Evidence-Based Medicine (CEBM) Levels of Evidence, 2011 version.

\section{Data Abstraction}

For eligible studies, data were extracted from the original articles, including publication year, country of origin, sample size, age, sex, histology, tumor location, neoadjuvant treatment, pathological $\mathrm{T}$ and $\mathrm{N}$ stage, definition of performed upper mediastinal lymphadenectomy, number of patients with pathologically positive nodes in the upper mediastinum, recurrent laryngeal nerve palsy rate, and survival. If data from any of the above items were not reported in the study, items were indicated as 'NR' (not reported). The extracted data were presented per study in tables. As the number of studies was limited and the variability in study design was considerable, no metaanalyses were performed. The Preferred Reporting Items for Systematic Reviews and Meta-Analyses (PRISMA) guidelines were followed for the conduction and reporting of this systematic review.

\section{RESULTS}

\section{Inclusion}

The primary literature search through the PubMed, Embase, and Cochrane libraries identified 543 studies. The search results and selection process are summarized in Fig. 1. The first screening discarded 496 papers, based on title and/or abstract, leaving 47 studies for full-text assessment. Thirty studies were excluded due to rates of upper mediastinal lymph node metastases not being reported $(n=19)$, mediastinal nodal status reported altogether without stratifying upper mediastinal lymph nodes $(n=5)$, reporting on fewer than 10 patients $(n=4)$, using the same case series as a more recent paper from the same authors $(n=1)$, and results not being reported in absolute numbers $(n=1)$. The remaining 17 studies ${ }^{15-31}$ were included in this review.

\section{Study Characteristics}

The included studies were published between 2000 and 2020. Patient demographic factors as well as tumor and treatment characteristics are presented in Tables 2 and 3, respectively. Of the 17 included studies, 11 $(65 \%)^{17-20,23,24,26,28-31}$ reported on Asian patient cohorts. Adenocarcinoma was the only histological subtype in 16 studies, and also represented $92 \%$ of the histological subtypes in one study. ${ }^{20}$ Furthermore, of the 17 included studies, $10(59 \%)^{15,19,20,22,24-27,29,30}$ included patients who received neoadjuvant treatment in varying proportions (see Table 3); one study pretreated the full cohort, ${ }^{15}$ while the remaining studies applied neoadjuvant treatment to $11-59 \%$ of the cohort. As shown in Table 4, the sample sizes of the cohorts who underwent esophagectomy with upper mediastinal lymphadenectomy for adenocarcinoma ranged from 10 to 634 patients.

\section{Primary Outcomes}

There was no uniform definition for upper mediastinal lymphadenectomy among the studies, as demonstrated by Table 4. Of the 17 included studies, only 7 $(41 \%)^{15,18,20,23,26,28,30}$ clearly specified which lymph node stations were dissected; one study ${ }^{15}$ followed the American Joint Committee on Cancer (AJCC) classification system to report the dissected lymph node stations, five studies $^{18,20,23,28,30}$ followed the Japan Esophageal Society (JES) classification, and one study ${ }^{26}$ used both classifications (Fig. 2). In the remaining 10 studies, ${ }^{16,17,19,21,22,24,25,27,29,31}$ the exact lymph node stations that were dissected as part of an upper mediastinal dissection were not defined.

Among all 17 included studies, the median number of upper mediastinal lymph node metastases was $10.0 \%$ (interquartile range [IQR] 4.7-16.7). In 9 of the 17 studies $(53 \%),{ }^{17,19,20,22,25,28-31}$ patients were selected to undergo upper mediastinal lymphadenectomy based on preoperative diagnostics, and, in those patients, the median number of tumor-positive lymph nodes was $8.9 \%$ (IQR 1.2-11.0). In the cohorts that reported unselected series of patients undergoing upper mediastinal lymphadenectomy, ${ }^{15,16,18,21,23,24,26,27}$ the median number of tumor-positive lymph nodes was $9.8 \%$ (IQR 4.4-20.0). 
FIG. 1 Flowchart systematic search

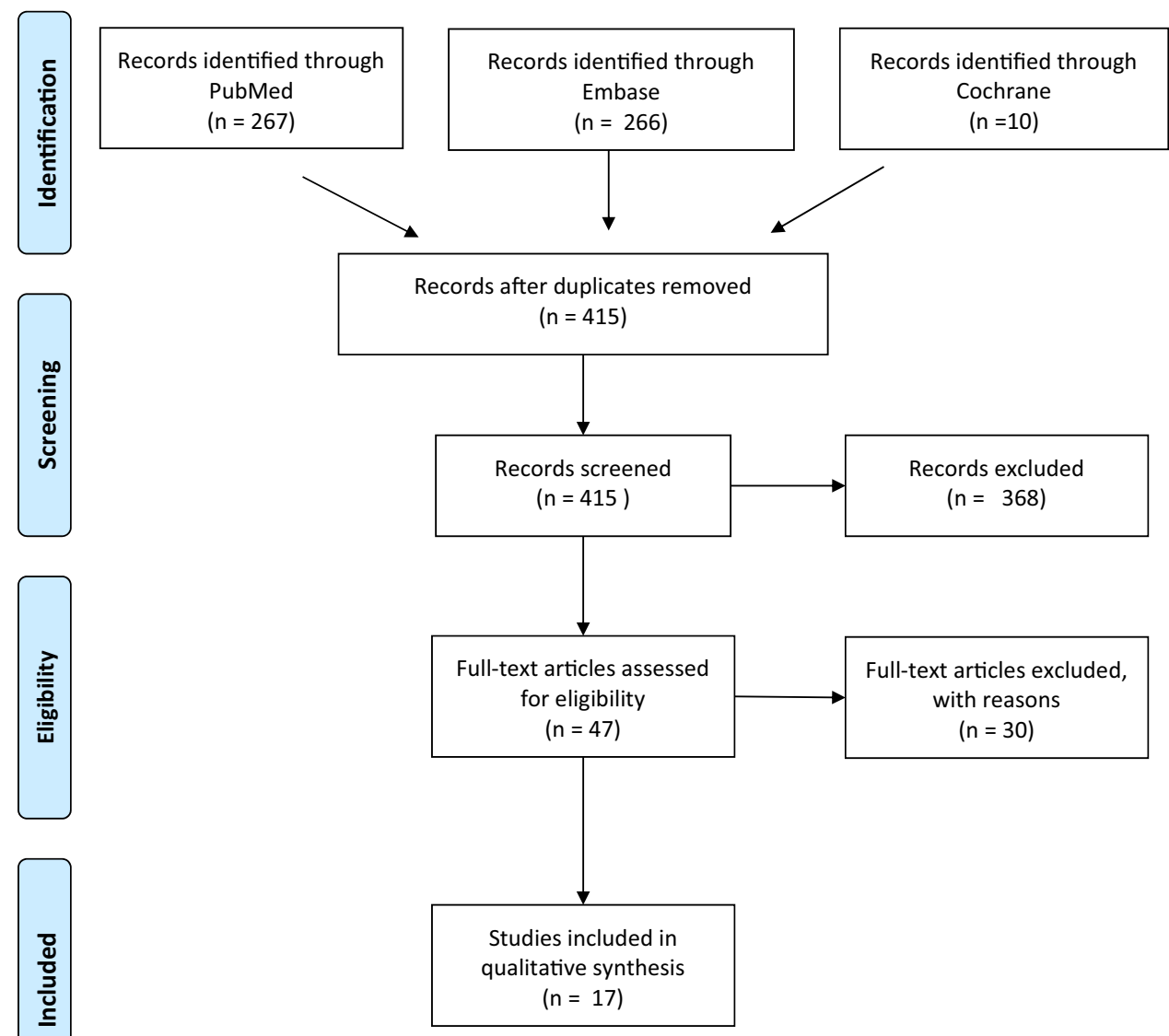

In the seven studies that reported on patients undergoing a primary resection, ${ }^{16-18,21,23,28,31}$ the median number of tumor-positive nodes in the upper mediastinum was $8.3 \%$ (IQR 2.0-16.6). In one study that applied neoadjuvant therapy to the full cohort, ${ }^{15}$ the incidence of tumor-positive nodes in the upper mediastinum was $4.4 \%$, while in nine studies that included patients treated with neoadjuvant treatment in varying proportions (11-59\%), 19,20,22,24-27,29,30 the median number of positive nodes in the proximal chest was $10.6 \%$ (IQR 8.9-15.8).

\section{Overall and Disease-Free Survival}

Survival data for patients with pathologically positive nodes in the upper mediastinum after esophagectomy were reported in six studies, as shown in Table 5. Two studies reported on 5-year overall survival that ranged between 17 and $44.4 \% .{ }^{19,26}$ One study ${ }^{15}$ reported a median disease-free survival of 15.4 months, while the remaining three studies reported on median survival ( 8 months) ${ }^{21} 5$-year diseasefree survival $(0 \%),{ }^{24}$ and 3 -year overall survival of $53 \%{ }^{30}$

\section{Recurrent Laryngeal Nerve Palsy Rate}

Only one study reported on the recurrent laryngeal nerve (RLN) palsy rate, which occurred in 8 of 129 patients in that study $(6.2 \%) .{ }^{20}$ Note that this rate was from all patients submitted to transthoracic esophagectomy in that case series, and was not specific for patients who received an upper mediastinal lymphadenectomy (67 patients in that group).

\section{DISCUSSION}

Based on this systematic review, the mean incidence of upper mediastinal lymph node metastases was up to $10 \%$ in patients undergoing transthoracic esophagectomy for distal esophageal or GEJ adenocarcinoma. Substantial variation was found in the reported incidences, which is probably at least partially explained by different definitions being used for an upper mediastinal lymphadenectomy. Furthermore, in most studies (9/17), selected patients underwent mediastinal lymph node dissection.

Transthoracic esophagectomy is currently considered to achieve the best oncological outcomes, as it allows a thorough mediastinal lymphadenectomy to maximize the 


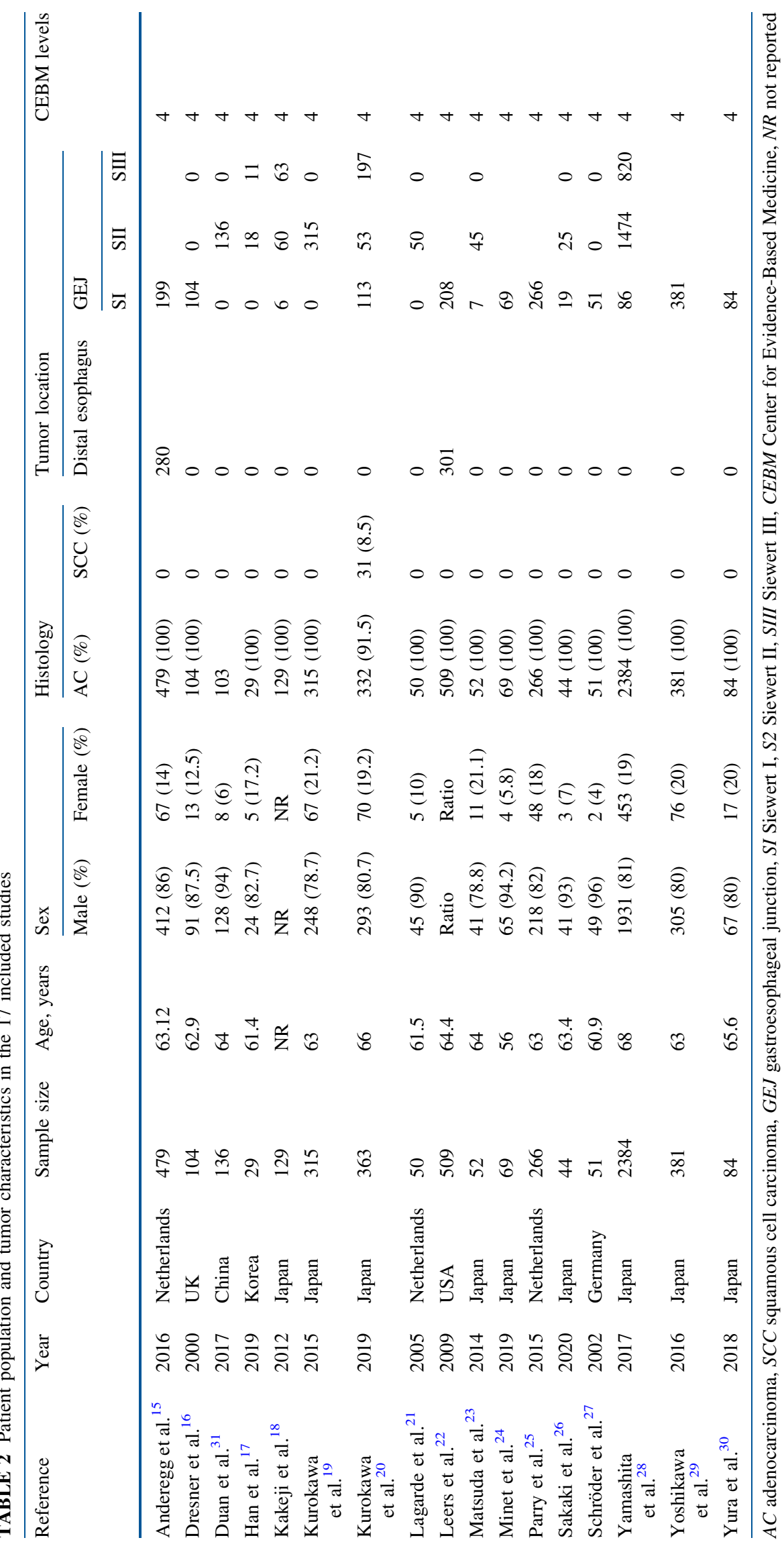


TABLE 3 Treatment characteristics and staging

\begin{tabular}{|c|c|c|c|c|c|c|c|c|c|}
\hline \multirow[t]{3}{*}{ Reference } & \multirow[t]{3}{*}{ Sample size } & \multicolumn{2}{|l|}{ Neoadjuvant treatment } & \multicolumn{6}{|c|}{ (y)pTNM stage } \\
\hline & & \multirow[t]{2}{*}{ Yes $(\%)$} & \multirow[t]{2}{*}{ No $(\%)$} & \multicolumn{3}{|l|}{$\mathrm{T}$} & \multicolumn{3}{|l|}{$\mathrm{N}$} \\
\hline & & & & T0-2 & T3-4 & Unknown & No & $\mathrm{N}+$ & Unknown \\
\hline Anderegg et al. ${ }^{15}$ & 479 & CT: 293 (61) CRT: 186 (39) & 0 & 193 & 283 & 3 & 226 & 253 & 0 \\
\hline Dresner et al. ${ }^{16}$ & 104 & NR & NR & NR & NR & NR & NR & 73 & NR \\
\hline Duan et al. ${ }^{31}$ & 136 & 0 & $136(100)$ & 17 & 118 & 0 & 44 & 92 & 0 \\
\hline Han et al. ${ }^{17}$ & 29 & 0 & $29(100)$ & 11 & 18 & 0 & 6 & 23 & 0 \\
\hline Kakeji et al. ${ }^{18}$ & 129 & 0 & $129(100)$ & 43 & 64 & 2 & $?$ & & \\
\hline $\begin{array}{l}\text { Kurokawa } \\
\text { et al. }{ }^{19}\end{array}$ & 315 & CT: 44 (14) & $271(86)$ & 57 & 258 & 0 & 75 & 240 & 0 \\
\hline $\begin{array}{c}\text { Kurokawa } \\
\text { et al. }\end{array}$ & 363 & $121(33.3)$ & $242(66.7)$ & 124 & 234 & 5 & 111 & 247 & 5 \\
\hline Lagarde et al. ${ }^{21}$ & 50 & 0 & $50(100)$ & 7 & 43 & 0 & 4 & 46 & 0 \\
\hline Leers et al. ${ }^{22}$ & 509 & $94(18.5)$ & $415(81.5)$ & NR & NR & NR & 241 & 268 & 0 \\
\hline Matsuda et al. ${ }^{23}$ & 52 & 0 & $52(100)$ & 22 & 30 & 0 & 20 & 32 & 0 \\
\hline Minet et al. ${ }^{24}$ & 69 & CT: 29 (42) & $40(58)$ & NR & NR & NR & NR & NR & NR \\
\hline Parry et al. ${ }^{25}$ & 266 & CT: 127 (48) RT: 1 CRT: 30 (11) & $108(41)$ & 29 & 65 & 6 no malign & 37 & 63 & 0 \\
\hline Sakaki et al. ${ }^{26}$ & 44 & CT: 15 (34) CRT: 1 & $28(64)$ & 11 & 33 & 0 & 11 & 33 & 0 \\
\hline Schröder et al. ${ }^{27}$ & 51 & CRT: 19 (37) & $32(63)$ & 26 & 25 & 0 & 23 & 28 & 0 \\
\hline $\begin{array}{l}\text { Yamashita } \\
\text { et al. }\end{array}$ & 2384 & 0 & $2384(100)$ & 1861 & 523 & 0 & 1708 & 676 & 0 \\
\hline $\begin{array}{l}\text { Yoshikawa } \\
\text { et al. }{ }^{29}\end{array}$ & 381 & CT: 41 (11) & $340(89)$ & 135 & 246 & 0 & 136 & 165 & 0 \\
\hline Yura et al. ${ }^{30}$ & 84 & $12(14)$ & $72(86)$ & 48 & 36 & 0 & 46 & 38 & 0 \\
\hline
\end{tabular}

$C T$ chemotherapy, $R T$ radiotherapy, $C R T$ chemoradiotherapy, $N R$ not reported

chances of removing all affected lymph nodes. Data regarding the optimal extent of lymphadenectomy for esophageal adenocarcinoma in the era of neoadjuvant treatment are contradictory. On the one hand, there is evidence in favor of extensive lymphadenectomy conferring survival benefit; a meta-analysis including 26 studies supported the benefit of an increased lymph node yield from esophagectomy for overall and disease- free survival, even after neoadjuvant treatment. ${ }^{4} \mathrm{~A}$ study in Asian subjects evaluated the impact of dissecting specific lymph node stations on survival and concluded that paratracheal lymphadenectomy has therapeutic value in patients with esophageal carcinoma; ${ }^{12}$ however, this study could not be included in the current systematic review since it mainly included patients with squamous cell carcinoma and did not separately report the outcomes of patients with adenocarcinoma. A significant overall survival benefit was not found in selected patients when comparing transhiatal resection with a limited lymphadenectomy versus transthoracic esophagectomy with an extended lymphadenectomy. ${ }^{32} \mathrm{~A}$ trend towards improved long-term survival at 5 years using the extended transthoracic approach compared with the limited transhiatal approach was found in another study. ${ }^{33}$ Nevertheless, data on dissecting specific lymph node stations are lacking and most surgeons do not routinely dissect the upper mediastinal lymph nodes for distal esophageal and GEJ tumors, as the balance between potential oncological merits and risk of recurrent laryngeal nerve injury is not clear. This systematic review found that the incidence of upper mediastinal lymph node metastasis is as high as $10 \%$ in these patients, suggesting that involvement of the upper mediastinal nodes may be present, even in distal adenocarcinomas.

Ideally, preoperative imaging should identify these lymph nodes, allowing surgeons to select patients who are most eligible for upper mediastinal lymphadenectomy. However, the reliability of clinical lymph node staging remains poor as the sensitivity of positron emission tomography/computed tomography (PET/CT) scanning for the detection of esophageal lymph node metastases is only 34-74\%. ${ }^{34}$ Although the sensitivity of endoscopic ultrasound (EUS) is somewhat higher for lymph nodes adjacent to the esophagus (75-84\%), this diagnostic modality has a considerably lower specificity (65-75\%) and is less accurate in identifying abnormal lymph nodes located more distantly. ${ }^{35,36}$ Although a combination of PET/CT and EUS 
TABLE 4 Sample size, definition and incidence of positive nodes in the upper mediastinum

\begin{tabular}{|c|c|c|c|c|c|}
\hline \multirow[t]{2}{*}{ Reference } & \multirow[t]{2}{*}{$N$} & \multirow[t]{2}{*}{$\begin{array}{l}\text { Definition of the upper mediastinal } \\
\text { lymphadenectomy performed }\end{array}$} & \multirow{2}{*}{$\begin{array}{l}\text { Patients with upper mediastinal } \\
\text { lymphadenectomy performed } \\
N\end{array}$} & \multicolumn{2}{|c|}{$\begin{array}{l}\text { Number of patients with positive } \\
\text { lymph node upper mediastinum }\end{array}$} \\
\hline & & & & $N$ & $\%$ \\
\hline Anderegg et al. ${ }^{15}$ & 479 & $\begin{array}{l}\text { Paratracheal (st } 2 \text { and } 4 \mathrm{R} \text { ), } \\
\text { aortapulmonary window (st 5) and } \\
\text { subcarinal (st } 7,10 \mathrm{r} \text { and } 101)\end{array}$ & 479 & $21 / 479$ & 4.4 \\
\hline Dresner et al. ${ }^{16}$ & 104 & Paratracheal & 104 & NR & 5 \\
\hline Duan et al. ${ }^{31}$ & 136 & Superior mediastinum & 10 & $1 / 10$ & 10 \\
\hline Han et al. ${ }^{17}$ & 29 & Upper mediastinum & 12 & $1 / 12$ & 8.3 \\
\hline Kakeji et al. ${ }^{18}$ & 129 & Upper mediastinal $(105,106)$ & 129 & NR & 2 \\
\hline Kurokawa et al. ${ }^{19}$ & 315 & Upper mediastinal & 18 & $3 / 18$ & 16.7 \\
\hline Kurokawa et al. $^{20}$ & 363 & $\begin{array}{l}\text { Upper mediastinal }(105,106 \mathrm{recL} \text {, } \\
\text { 106recR) }\end{array}$ & 67 & $6 / 67$ & 8.9 \\
\hline Lagarde et al. ${ }^{21}$ & 50 & $\begin{array}{l}\text { Proximal lymph nodes: right paratracheal, } \\
\text { aortopulmonary window and subcarinal }\end{array}$ & 50 & $11 / 50$ & 22 \\
\hline Leers et al. ${ }^{22}$ & 509 & Paratracheal & 250 & $3 / 250$ & 1.2 \\
\hline Matsuda et al. ${ }^{23}$ & 52 & 105, 106recR, 106recL & 52 & $4 / 52$ & 16.6 \\
\hline Mine et al. ${ }^{24}$ & 69 & $\begin{array}{l}\text { Upper mediastinal (above tracheal } \\
\text { bifurcation) }\end{array}$ & 69 & $14 / 69$ & 20 \\
\hline Parry et al. ${ }^{25}$ & 266 & $\begin{array}{l}\text { Upper mediastinal (paratracheal, } \\
\text { aortapulmonary window, subcarinal) }\end{array}$ & 111 & NR & 11 \\
\hline Sakaki et al. ${ }^{26}$ & 44 & $\begin{array}{l}\text { Upper mediastinal }(105,106 \mathrm{recL} \\
\text { 106recR, 106tbL) }\end{array}$ & 44 & $12 / 44$ & 27.3 \\
\hline Schröder et al. ${ }^{27}$ & 51 & Upper mediastinum & 51 & $5 / 51$ & 9.8 \\
\hline Yamashita et al. $^{28}$ & 2384 & Upper mediastinal $(105,106 r, 106 t b)$ & 634 & $3 / 634$ & 0.4 \\
\hline Yoshikawa et al. $^{29}$ & 381 & Upper mediastinal nodes & 19 & $3 / 19$ & 15.8 \\
\hline Yura et al. ${ }^{30}$ & 84 & $105+106$ & 30 & $5 / 30$ & 16.6 \\
\hline
\end{tabular}

$N R$ not reported

is used in some centers for preoperative lymph node staging, diagnostic accuracy is generally considered to be insufficient to perform a targeted lymph node dissection. This could be an argument for esophagectomy with routine removal of all mediastinal lymph nodes at risk, including those located in the upper mediastinum. On the other hand, increased understanding of metastatic patterns based on tumor characteristics might carry potential to guide decision making. In a nationwide Japanese study that was included in this systematic review, it was shown that lymph node metastases in JES stations 105, 106L, and 106R (which correspond to AJCC stations 2 and 4) occurred in $0 \%, 0 \%$, and $3 \%$, respectively, of patients with GEJ adenocarcinoma or squamous cell carcinoma that extended $<4 \mathrm{~cm}$ in the esophagus. ${ }^{20}$ Such insights, which are expected to be amplified within the next years by initiatives such as the TIGER trial (NCT03222895), ${ }^{37}$ might shed light on indications for performing a less aggressive lymph node dissection in particular subgroups in the future.

Although upper mediastinal lymph node metastases are observed in up to $10 \%$ of patients with distal esophageal adenocarcinoma, the impact of upper mediastinal lymphadenectomy on survival remains unclear based on this systematic review. Hence, high-quality evidence on this topic is lacking and more research is needed to evaluate the clinical value of upper mediastinal lymphadenectomy. Even if future studies are able to identify an association between upper mediastinal lymphadenectomy and survival after esophagectomy for adenocarcinoma, investigators should be aware of the phenomenon referred to as stage migration, which may be the result of harvesting more lymph nodes. ${ }^{38}$ Future studies should thus strive to improve our understanding of the role of upper mediastinal lymphadenectomy on staging and survival in patients undergoing esophagectomy for adenocarcinoma.

With potential survival benefits on one side of the scale, the risk of complications should be weighed up against the other. As paratracheal stations 2 and 4 are adjacent to the RLNs, dissection of this region might increase the risk of iatrogenic RLN injury, with reported incidences in experienced centers ranging from 5 to $26 \% .{ }^{39-41}$ RLN injury can result in hoarseness and difficulty swallowing, which reduces quality of life and increases the risk of aspiration 
FIG. 2 Anatomical representation and incidence of positive nodes as reported by 7 of the 17 included studies that clearly defined the performed upper mediastinal dissection. LN lymph node, Neoadj treat neoadjuvant treatment

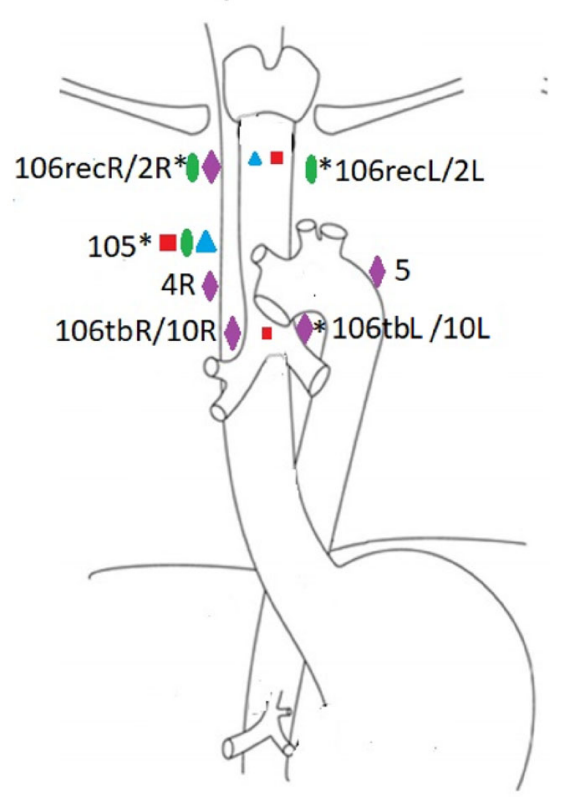

\begin{tabular}{|c|c|c|c|c|}
\hline Ref. & Dissected LN stations & $\begin{array}{l}\text { Incidence positive } \\
\text { nodes }\end{array}$ & $\begin{array}{l}\text { Neoadj treat } \\
\text { (\%) }\end{array}$ & Symbol \\
\hline Anderegg et al15 & $2 \mathrm{R}, 4 \mathrm{R}, 10 \mathrm{R}, 10 \mathrm{~L}, 5$ & $4.4 \%$ & Yes (100\%) & \\
\hline Kurokawa et al19 & $105,106 \mathrm{recR}, 106 \mathrm{recL}$ & $16.7 \%$ & Yes (14\%) & \\
\hline Matsuda et $a^{23}$ & $105,106 \mathrm{recR}, 106 \mathrm{rec}$ & $16.6 \%$ & No & \\
\hline Sakaki et al26 & $\begin{array}{l}\text { 105, 106recR, 106recL, } \\
\text { 106tbL }\end{array}$ & $27.3 \%$ & Yes (36\%) & * \\
\hline Yamashita et al28 & $105,106 \mathrm{tb}, 106 \mathrm{r}$ & $0.4 \%$ & No & \\
\hline Yura et $a^{30}$ & 105,106 & $16.6 \%$ & Yes (14\%) & \\
\hline Kakeji et al18 & 105,106 & $2 \%$ & No & \\
\hline
\end{tabular}

TABLE 5 Survival data from patients with pathologically positive nodes in the upper mediastinum after esophagectomy

\begin{tabular}{|c|c|c|c|c|}
\hline Reference & 5-year OS (\%) & 5-year DFS (\%) & Median survival (months) & Median DFS (months) \\
\hline $\begin{array}{l}\text { Anderegg } \\
\text { et al. }^{15}\end{array}$ & NR & NR & NR & 15.4 \\
\hline $\begin{array}{c}\text { Kurokawa } \\
\text { et al. }{ }^{19}\end{array}$ & $17 \%$ & NR & NR & NR \\
\hline Minet et al. ${ }^{24}$ & NR & $0 \%$ & NR & NR \\
\hline Lagarde et al. ${ }^{21}$ & NR & NR & $\begin{array}{l}\mathrm{N}+\text { proximal chest: } 8 \\
\mathrm{~N}-\text { proximal chest: } 25\end{array}$ & NR \\
\hline Sakaki et al. ${ }^{26}$ & $41.7-44.4$ & NR & NR & NR \\
\hline Yura et al. ${ }^{30}$ & 53.3 (3 years) & NR & NR & NR \\
\hline
\end{tabular}

$O S$ overall survival, $D F S$ disease-free survival, $N R$ not reported

pneumonia. $^{42}$ Although paratracheal lymphadenectomy may be especially challenging after neoadjuvant chemoradiotherapy and requires a learning curve, studies by a Taiwanese group showed that it is safe in experienced hands. ${ }^{39,43}$ Therefore, surgeons should consider a thorough teaching program when starting to perform a full 
paratracheal lymphadenectomy as part of transthoracic esophagectomy. Moreover, the technical benefits of robotic surgery in the form of enhanced three-dimensional view and improved dexterity by Endo-Wrist technology might improve the safety of an upper mediastinal dissection. This hypothesis is currently being investigated in a randomized controlled trial by the same Taiwanese group, which compares the effectiveness and RLN palsy rates in robotic versus thoracoscopic esophagectomy with paratracheal lymphadenectomy. ${ }^{44}$

The strength of this study is its clinical relevance, as it represents the first systematic review that aims to provide insight into the value of upper mediastinal lymphadenectomy for patients undergoing esophagectomy for adenocarcinoma with and without neoadjuvant therapy. One of the limitations of the study is the heterogeneity in neoadjuvant treatment and patient selection. Another limitation seems to be the wide variation in definitions that were used for an upper mediastinal lymphadenectomy in the existing literature, which in fact highlights the low level of evidence on the topic at this moment. In the absence of studies that are suitable for pooling of data in order to generate a reasonable level of evidence, esophageal surgeons are currently operating mainly based on their personal convictions or those of their former teachers. To increase the transparency and comparability of studies on this topic, future studies should report the exact lymph node stations that are part of the lymphadenectomy. Furthermore, the authors suggest the dissection of stations 2 and 4 in both sides as the only definition of a full upper mediastinal lymphadenectomy as part of a total mediastinal lymphadenectomy. By increasing the number of comparable studies, it will be possible to establish evidence-based recommendations on this topic.

\section{CONCLUSION}

This study demonstrates that the incidence of upper mediastinal lymph node metastases is up to $10 \%$ in patients undergoing transthoracic esophagectomy for distal esophageal or GEJ adenocarcinoma. The diagnostic accuracy of current imaging techniques is insufficient for the detection of upper mediastinal lymph node metastases, and the effect of neoadjuvant treatment on node positivity in this region is unclear. Although the impact on overall survival is not clear, if morbidity could be reduced, surgeons could consider standard upper mediastinal lymphadenectomy for distal esophageal adenocarcinoma to potentially improve the oncological outcome.

DISCLOSURES Jelle Ruurda and Richard van Hillegersberg are proctors for Intuitive Surgical Inc. Amaia Gantxegi, B. Feike Kingma,
Grard A.P. Nieuwenhuijzen, and Misha D.P. Luyer have no disclosures to declare.

OPEN ACCESS This article is licensed under a Creative Commons Attribution 4.0 International License, which permits use, sharing, adaptation, distribution and reproduction in any medium or format, as long as you give appropriate credit to the original author(s) and the source, provide a link to the Creative Commons licence, and indicate if changes were made. The images or other third party material in this article are included in the article's Creative Commons licence, unless indicated otherwise in a credit line to the material. If material is not included in the article's Creative Commons licence and your intended use is not permitted by statutory regulation or exceeds the permitted use, you will need to obtain permission directly from the copyright holder. To view a copy of this licence, visit http://creativecommons. org/licenses/by/4.0/.

\section{REFERENCES}

1. Shapiro J, van Lanschot JJB, Hulshof MCCM, et al. Neoadjuvant chemoradiotherapy plus surgery versus surgery alone for oesophageal or junctional cancer (CROSS): long-term results of a randomised controlled trial. Lancet Oncol. 2015;16(9):1090-8.

2. van der Sluis PC, Ruurda JP, Verhage RJJ, et al. Oncologic longterm results of robot-assisted minimally invasive thoraco-laparoscopic esophagectomy with two-field lymphadenectomy for esophageal cancer. Ann Surg Oncol. 2015;22:1350-6.

3. Haverkamp L, Seesing MFJ, Ruurda JP, Boone J, van Hillegersberg R. Worldwide trends in surgical techniques in the treatment of esophageal and gastroesophageal junction cancer. Dis Esophagus. 2017;30(1):1-7.

4. Visser E, Markar SR, Ruurda JP, Hanna GB, van Hillegersberg R. Prognostic value of lymph node yield on overall survival in esophageal cancer patients: a systematic review and meta-analysis. Ann Surg. 2019;269(2):261-8.

5. Visser E, Rossum PSNV, Ruurda JP, Van Hillegersberg R. Impact of lymph node yield on overall survival in patients treated with neoadjuvant chemoradiotherapy followed by esophagectomy for cancer. Ann Surg. 2017;266(5):863-9.

6. Amin MB, Edge SBGF. The AJCC cancer staging manual. 8th edn. Springer; 2016.

7. Japanese Classification of Esophageal Cancer. 11th Edition: part II and III. Esophagus. 2017;14(1):37-65. https://doi.org/10.1007/ s10388-016-0556-2.

8. Cuesta MA, van der Wielen N, Weijs TJ, et al. Surgical anatomy of the supracarinal esophagus based on a minimally invasive approach: vascular and nervous anatomy and technical steps to resection and lymphadenectomy. Surg Endosc. 2017;31(4):1863-70.

9. van der Horst S, Weijs TJ, Ruurda JP, et al. Robot-assisted minimally invasive thoraco-laparoscopic esophagectomy for esophageal cancer in the upper mediastinum. J Thorac Dis. 2017;9:S834-42.

10. Cuesta MA, Weijs TJ, Bleys RLAW, et al. A new concept of the anatomy of the thoracic oesophagus: the meso-oesophagus. Observational study during thoracoscopic esophagectomy. Surg Endosc. 2015;29(9):2576-82.

11. Parry K, Haverkamp L, Bruijnen RCG, et al. Staging of adenocarcinoma of the gastroesophageal junction. Eur J Surg Oncol. 2016;42(3):400-6.

12. Miyata H, Sugimura K, Yamasaki M, et al. Clinical impact of the location of lymph node metastases after neoadjuvant 
chemotherapy for middle and lower thoracic esophageal cancer. Ann Surg Oncol. 2019;26(1):200-8.

13. Phillips AW, Lagarde SM, Navidi M, Disep B, Griffin SM. Impact of extent of lymphadenectomy on survival, post neoadjuvant chemotherapy and transthoracic esophagectomy. Ann Surg. 2017;265(4):750-6.

14. Hagens ERC, van Berge Henegouwen MI, Cuesta MA, Gisbertz SS. The extent of lymphadenectomy in esophageal resection for cancer should be standardized. J Thorac Dis. 2017;9:S713-23.

15. Anderegg MCJ, Lagarde SM, Jagadesham VP, et al. Prognostic significance of the location of lymph node metastases in patients with adenocarcinoma of the distal esophagus or gastroesophageal junction. Ann Surg. 2016;264(5):847-53.

16. Dresner SM, Lamb PJ, Bennett MK, Hayes N, Griffin SM. The pattern of metastatic lymph node dissemination from adenocarcinoma of the esophagogastric junction. Surgery. 2001;129(1):103-9.

17. Han WH, Eom BW, Yoon HM, et al. The optimal extent of lymph node dissection in gastroesophageal junctional cancer: retrospective case control study. BMC Cancer. 2019;19(1):719.

18. Kakeji $\mathrm{Y}$, Yamamoto $\mathrm{M}$, Ito $\mathrm{S}$, et al. Lymph node metastasis from cancer of the esophagogastric junction, and determination of the appropriate nodal dissection. Surg Today. 2012;42(4):351-8.

19. Kurokawa Y, Hiki N, Yoshikawa T, et al. Mediastinal lymph node metastasis and recurrence in adenocarcinoma of the esophagogastric junction. Surgery. 2015;157(3):551-5.

20. Kurokawa Y, Takeuchi H, Doki Y, et al. Mapping of lymph node metastasis from esophagogastric junction tumors. Ann Surg. 2021;274(1):120-7. https://doi.org/10.1097/sla.0000000000003499.

21. Lagarde SM, Cense HA, Hulscher JBF, et al. Prospective analysis of patients with adenocarcinoma of the gastric cardia and lymph node metastasis in the proximal field of the chest. Br J Surg. 2005;92(11):1404-8.

22. Leers JM, DeMeester SR, Chan N, et al. Clinical characteristics, biologic behavior, and survival after esophagectomy are similar for adenocarcinoma of the gastroesophageal junction and the distal esophagus. $J$ Thorac Cardiovasc Surg. 2009;138(3):594-602.

23. Matsuda T, Takeuchi H, Tsuwano S, Nakahara T, Mukai M, Kitagawa Y. Sentinel node mapping in adenocarcinoma of the esophagogastric junction. World J Surg. 2014;38(9):2337-44.

24. Minet S, Watanabe M, Kumagai K, et al. Comparison of mediastinal lymph node metastases from adenocarcinoma of the esophagogastric junction versus lower esophageal squamous cell carcinoma with involvement of the esophagogastric junction. Dis Esophagus. 2019;32(11):doz002.

25. Parry K, Haverkamp L, Bruijnen RCG, Siersema PD, Ruurda JP, van Hillegersberg R. Surgical treatment of adenocarcinomas of the gastro-esophageal junction. Ann Surg Oncol. 2015;22(2):597-603.

26. Sakaki A, Kanamori J, Ishiyama K, Kurita D, Oguma J, Daiko H. Distribution of lymph node metastases in locally advanced adenocarcinomas of the esophagogastric junction (cT2-4): comparison between Siewert type I and selected Siewert type II tumors. Langenbeck's Arch Surg. 2020;405(4):509-19.

27. Schröder W, Mönig SP, Baldus SE, Gutschow C, Schneider PM, Hölscher AH. Frequency of nodal metastases to the upper mediastinum in Barrett's cancer. Ann Surg Oncol. 2002;9(8):807-11.

28. Yamashita H, Seto Y, Sano T, Makuuchi H, Ando N, Sasako M. Results of a nation-wide retrospective study of lymphadenectomy for esophagogastric junction carcinoma. Gastric Cancer. 2017;20:69-83.

29. Yoshikawa T, Takeuchi H, Hasegawa S, et al. Theoretical therapeutic impact of lymph node dissection on adenocarcinoma and squamous cell carcinoma of the esophagogastric junction. Gastric Cancer. 2016;19(1):143-9.
30. Yura M, Takeuchi H, Fukuda K, et al. High-risk group of upper and middle mediastinal lymph node metastasis in patients with esophagogastric junction carcinoma. Ann Gastroenterol Surg. 2018;2(6):419-27.

31. Duan XF, Yue J, Tang P, Bin Shang X, Jiang HJ, Yu ZT. Lymph node dissection for Siewert II esophagogastric junction adenocarcinoma: a retrospective study of 3 surgical procedures. Medicine. 2017;96(7):e6120.

32. Omloo JMT, Lagarde SM, Hulscher JBF, et al. Extended transthoracic resection compared with limited transhiatal resection for adenocarcinoma of the mid/distal esophagus: five-year survival of a randomized clinical trial. Ann Surg. 2007;246(6):992-1001.

33. Hulscher JBF, van Sandick JW, de Boer AGEM, et al. Extended transthoracic resection compared with limited transhiatal resection for adenocarcinoma of the esophagus. $N$ Engl $\mathrm{J} \mathrm{Med}$. 2002;347(21):162-9. https://doi.org/10.1056/nejmoa022343.

34. Shi W, Wang W, Wang J, Cheng H, Huo X. Meta-analysis of 18FDG PET-CT for nodal staging in patients with esophageal cancer. Surg Oncol. 2013;22(2):112-6.

35. Van Vliet EPM, Heijenbrok-Kal MH, Hunink MGM, Kuipers EJ, Siersema PD. Staging investigations for oesophageal cancer: a meta-analysis. Br J Cancer. 2008;98(3):547-57.

36. Goense L, van Rossum PSN, Kandioler D, et al. Stage-directed individualized therapy in esophageal cancer. Ann N Y Acad Sci. 2016;1381(1):50-65.

37. Hagens ERC, Van Berge Henegouwen MI, Van Sandick JW, et al. Distribution of lymph node metastases in esophageal carcinoma [TIGER study]: study protocol of a multinational observational study. BMC Cancer. 2019;19(1):662.

38. Hulscher JBF, Van Sandick JW, Offerhaus GJA, Tilanus HW, Obertop H, Van Lanschot JJB. Prospective analysis of the diagnostic yield of extended en bloc resection for adenocarcinoma of the oesophagus or gastric cardia. Br J Surg. 2001;88(5):715-9. h ttps://doi.org/10.1046/j.1365-2168.2001.01746.x.

39. Chiu CH, Wen YW, Chao YK. Lymph node dissection along the recurrent laryngeal nerves in patients with oesophageal cancer who had undergone chemoradiotherapy: is it safe? Eur J CardioThorac Surg. 2018;54(4):657-63.

40. Chao YK, Chiu CH, Liu YH. Safety and oncological efficacy of bilateral recurrent laryngeal nerve lymph-node dissection after neoadjuvant chemoradiotherapy in esophageal squamous cell carcinoma: a propensity-matched analysis. Esophagus. 2020;17(1):33-40. https://doi.org/10.1007/s10388-019-00688-7.

41. van der Sluis PC, van der Horst S, May AM, et al. Robot-assisted minimally invasive thoracolaparoscopic esophagectomy versus open transthoracic esophagectomy for resectable esophageal cancer: a randomized controlled trial. Ann Surg. 2019;269(4):621-30.

42. Scholtemeijer MG, Seesing MFJ, Brenkman HJF, Janssen LM, van Hillegersberg R, Ruurda JP. Recurrent laryngeal nerve injury after esophagectomy for esophageal cancer: incidence, management, and impact on shortand long-term outcomes. J Thorac Dis. 2017;9:S868-78.

43. Chao YK, Wen YW, Chuang WY, Cerfolio RJ. Transition from video-assisted thoracoscopic to robotic esophagectomy: a single surgeon's experience. Dis Esophagus. 2020;33(2):doz033.

44. Chao YK, Li ZG, Wen YW, et al. Robotic-assisted esophagectomy vs video-assisted thoracoscopic esophagectomy (REVATE): study protocol for a randomized controlled trial. Trials. 2019;20(1):346.

Publisher's Note Springer Nature remains neutral with regard to jurisdictional claims in published maps and institutional affiliations. 